Cómo citar este artículo en Chicago: Gama, Luis Eduardo. "El método hermenéutico de Hans-Georg Gadamer”. Escritos 29, no. 62 (2021): 17-32. doi: http://dx.doi.org/10.18566/escr.v29n62.a02

Fecha de recepción: 26.01 .2021

Fecha de aceptación: 01.03.2021

\title{
El método hermenéutico de Hans-Georg Gadamer
}

\author{
Hermeneutic Method of Hans-Georg Gadamer
}

\author{
Luis Eduardo Gama ${ }^{1}$
}

\section{RESUMEN}

Se asume con frecuencia que la filosofía hermenéutica de Hans-Georg Gadamer está construida sobre la base de una poderosa crítica al método de las ciencias naturales que al apropiarse del monopolio de lo que sería un verdadero conocimiento cerraría las puertas a otras formas no científicas de experiencias de la verdad. Este artículo se propone, en una primera parte, examinar este supuesto a partir de un análisis de la dialéctica hermenéutica y la ontología del lenguaje que Gadamer plantea en la tercera parte de su obra capital Verdad y método. El resultado de este análisis mostrará que la crítica gadameriana al metodologismo científico se elabora, en último término, sobre el trasfondo de una concepción del ser en tanto acontecer de sentido, y del ser humano como individuo cuya comprensión de mundo es interpelada y movida desde este acontecer. Estos planteamientos ontológicos sirven para perfilar los rasgos generales de lo que sería para este autor un verdadero método del pensar y de su acceso a la verdad. Con estos resultados, el artículo se propone, en su segunda parte, identificar tres principios metodológicos elementales que determinarían el ejercicio de un genuino pensar hermenéutico: a) el principio de determinación del topos de la comprensión, que exige poner de manifiesto las relaciones de sentido que nos vinculan con lo que queremos comprender; b) el principio de corrección que permite que toda comprensión "mejore" permanentemente tanto nuestra interpretación de las cosas como la auto-descripción que los actores hacen de sus propios actos, y c) el principio de la sensibilidad para el acontecer que demanda una escucha atenta de todas las posibles relaciones de sentido que configuran los fenómenos, así como de las constantes variaciones y mutaciones de sentido que ellos experimentan.

Palabras clave: Hermenéutica; Método; Dialéctica; Lenguaje; Pertenencia; Historia efectual; Acontecer de sentido; Comprensión; Anticipación de la perfección; Escucha hermenéutica.

1 Doctor en Filosofía por la Ruprecht-Karl Universität Heidelberg, Alemania. Profesor asociado de la Universidad Nacional de Colombia. Correo electrónico: legamab@unal.edu.co. 


\begin{abstract}
It is commonly argued that Hans-Georg Gadamer's hermeneutics rests upon a criticism of the method of natural sciences that, by establishing a monopoly of what might be deemed as true knowledge, would exclude different forms of non-scientific experiences of truth. Thus, the article aims first at examining this assumption based on an analysis of his hermeneutic dialectics and ontology of language, which he develops in the third part of Truth and Method. This analysis reveals that his criticism of scientific method rests upon the idea that the being is related to the happening of meaning and of human beings as individuals whose understanding of the world is questioned and caused by such happening. These ontological approaches make possible to characterize what might be the true method of thinking and access to truth. Secondly, the article aims at identifying three methodological principles that would guide a genuine exercise of hermeneutic thinking: a) The principle of determining the topos of understanding, which demands to reveal the relations of meaning that connect us to what we desire to understand; b) Principle of correction, which makes possible that understanding continuously "improves" both our interpretations and self-descriptions that actors provide of their own actions; and c) Principle of sensitivity towards happening, which demands to carefully listen to every possible relation of meaning that shape phenomena, as well as to the variations and mutations of meaning they experience.
\end{abstract}

Keywords: Hermeneutics; Method; Dialectics; Language; Belonging; Effective History; Happening of Meaning; Understanding; Anticipation of Completeness; Hermeneutic Listening.

\title{
Introducción
}

$\mathrm{E}$ 1 título de este artículo parece encerrar un malentendido o una provocación. Afirmar la existencia de un "método hermenéutico" ¿no implica desconocer en Gadamer al crítico acérrimo del metodologismo moderno que, apoyado en el auge de las ciencias naturales, se extendió por todas los campos del saber hasta hacerse valer como la única vía de acceso al genuino conocimiento?, ¿no defiende su hermenéutica la especificidad de las llamadas ciencias del espíritu que consiste justamente en no depender del método causal explicativo, sino en llevar a sus últimas consecuencias esa forma de apertura de mundo que realiza el existir humano y que se llama el comprender?, ¿no resulta tan acérrima su oposición al método hasta el punto de que muchos han sugerido que su obra capital debería llamarse en realidad "verdad versus método".

Vale la pena, sin embargo, detenerse a examinar en detalle esta opinión extendida. Aquí nos proponemos realizar este examen en dos etapas. Primero, revisaremos, al hilo de algunas observaciones de Verdad y método, la verdadera postura de Gadamer frente al método propio de las ciencias modernas. Con ello ganaremos una visión más objetiva sobre su presunto antimetodologismo. En este contexto, será claro que el trasfondo de su crítica al objetivismo del método científico resulta ser ciertos planteamientos ontológicos desde los cuales es posible perfilar lo que para Gadamer sería el "verdadero método" de la comprensión, un método que, como veremos, entiende como una forma de dialéctica. Segundo, extraeremos de esa dialéctica orientaciones más precisas para un método del pensamiento filosófico de estirpe hermenéutica.

Centraremos este estudio en la parte tercera de Verdad y método donde la cuestión de la comprensión de las ciencias del espíritu ha dado ya un giro hacia la ontología. En esta sección, la polémica contra el 
método ya no se realizará en el terreno "epistemológico" que busca limitar el predominio de la explicación causal, sino que encuentra sus raíces ontológicas más profundas. En este contexto, Gadamer afirma:

Nuestro punto de partida había sido la insuficiencia del moderno concepto de método. Sin embargo, la justificación filosófica más importante de esta insuficiencia es la apelación expresa al concepto griego de método por parte de Hegel. Con su concepto de la "reflexión externa" Hegel critica este concepto del método como realización de una acción ajena a las cosas. El verdadero método sería el hacer de la cosa misma”."

Como vemos, no se trata ya de sustentar la debilidad del método moderno en su incapacidad para aprehender el sentido de la acción histórica del ser humano o, lo que es igual, en su imposibilidad de referir lo cambiante del mundo espiritual de los hombres a ciertas regularidades y leyes constantes universales. Ahora se trata de una razón filosófica más honda: el método moderno falla porque es un hacer forzado, impuesto externamente, sobre las cosas y no expresión de las cosas mismas. Se mencionan aquí dos elementos estrechamente vinculados que conviene, sin embargo, examinar por separado. En primera instancia, se critica el método científico por su carácter externo y, luego, por desconocer la "acción de las cosas mismas".

En cuanto al primer punto, Gadamer relaciona este hacer externo con el proceso de objetivación de la realidad, que constituye el momento inicial de la explicación científica. Objetivar la realidad significa hacerla objeto para una consciencia que entonces ya no se encuentra vinculada con su objeto, sino que se sitúa en un punto de vista neutral desde el que puede aprehender las genuinas determinaciones de lo real, para formularlas luego al modo de leyes universales que dan cuenta de sus conexiones causales internas. Visto así este hacer es arbitrario (VM, 555) porque modela la realidad desde esquemas nomológicos impostados, pero, además, porque al hacer esto desconoce la pertenencia del sujeto conocedor al objeto de conocimiento ( $V M, 550)$. La referencia a Hegel en este pasaje se entiende en este contexto: para Hegel, el método moderno no solo extrae a la consciencia de su pertenencia al entramado racional del todo que él llama espíritu, sino que fragmenta la unidad de este en entidades aisladas que solo se enlazan luego de manera causal. Este olvido del espíritu y el desconocimiento de nuestra pertenencia a este constituye la objeción filosófica más aguda en contra de la empresa de dominación de lo ente que es la ciencia moderna; no se trata en Hegel, ni en Gadamer por cierto, de negar los avances civilizatorios que la objetivación científica del mundo ha traído consigo, pero al desconocer al espíritu la ciencia lo depotencia, inhibe su presencia efectiva en el ser de lo real y enajena al ser humano al situarlo en medio de un mundo mecanizado y sin vida. En ese sentido, la polémica hegeliana contra la ciencia reviste un alcance metafísico: ella promueve un hacer del ser humano y una postura ante el mundo que, tal vez sin proponérselo, obstaculiza la manifestación efectiva del concepto (Begriff), es decir, la espiritualización de lo real que es para Hegel el despliegue y la verdadera realización del ser. Y con esto ya hemos tocado el segundo punto de la crítica al metodologismo científico, pues el hacer de la "cosa misma" que este desconoce no es otro en Hegel que este hacer mismo del concepto: el autodesarrollo de la idea que como espíritu real va ganando consciencia de sí a medida que se interna en el ser histórico concreto, con lo que determina de manera cada vez más transparente las formas de vida de los individuos.

No obstante su explícita impronta hegeliana, la discusión de Gadamer con el método científico no sigue a Hegel a pie juntillas. Es verdad que para la hermenéutica la ciencia moderna, por impresionantes que

2 Hans-Georg Gadamer, Verdad y método I (Salamanca: Sígueme, 1996), 555 (citado a partir de ahora en el texto como VM). 
resulten sus logros materiales, no proporciona más que un saber exterior sobre las cosas que no penetra en la profundidad de sentido de lo real, así como también resulta cierto que ella misma, en consonancia con Hegel, parte del presupuesto ontológico de una pertenencia del Dasein al mundo que el dualismo metodológico entre sujeto y objeto claramente desconoce. No obstante, existe aquí una diferencia fundamental, pues el trasfondo de la crítica hermenéutica a la ciencia ya no es la metafísica hegeliana del espíritu. En ese sentido, también para Gadamer, el "verdadero método" es un "hacer de las cosas mismas" y no la actividad objetivante de una consciencia científica, pero lo que se entiende por las "cosas mismas" no remite al concepto hegeliano que como idea permea la totalidad de la naturaleza y la historia, sino algo que proviene de una ontología de cuño muy diferente. Por ello, Gadamer señala en este contexto que la hermenéutica también se limita, como Hegel, a "guiarse por la necesidad de las cosas", pero tal necesidad no procede del autodespliegue del Geist, sino del movimiento del lenguaje, y desde él "el concepto de pertenencia no se determina ya como referencia teleológica del espíritu a la estructura esencial de los entes tal como se piensa en la metafísica" (VM, 552).

Para comprender estas últimas observaciones, debemos examinar de qué manera Gadamer concibe esta pertenencia del ser humano al mundo y lallamada "acción de las cosas mismas" que determina al "verdadero método". Para ello, recurriremos a la noción de dialéctica a la que se apela en estos pasajes. En efecto, en un gesto propio de su manera de concebir la filosofía, Gadamer quiere entroncar su pensamiento con la tradición filosófica occidental al entender su propia reflexión como una forma de dialéctica, y así entrar en diálogo con un problema clásico de toda la metafísica desde la antigüedad. De esta forma, además, se busca conferir a la polémica contra el método su significación más profunda que va más allá de un mero asunto epistemológico (cf. $V M, 551$ ). La cuestión de la dialéctica, en efecto, no representó para los griegos un asunto menor que concerniera solo a la forma exterior del pensar filosófico. Por el contrario, en ella se recogía su intuición metafísica fundamental según la cual el pensamiento y el conocimiento son momentos del ser mismo. En esa medida, los griegos no intentaron fundar el conocimiento desde un pensar solo subjetivo, sino que hicieron de este una realización propia del ser mismo o, lo que es igual, consideraron que el pensamiento humano solo alcanza su más genuina esencia cuando se vincula al movimiento mismo del logos que articula toda la realidad. Es esta la esencia última de la dialéctica griega, su fundamento metafísico del que luego pueden derivar ciertas orientaciones "metódicas", como cuando Platón pide a los jóvenes con los que dialoga no inmiscuir sus propias ocurrencias en el curso de las cosas, o cuando los desconcierta con sus preguntas para hacerles ver lo infundado de sus opiniones naturales y orientarlos hacia el asunto mismo del que se habla. En estas observaciones, se perfila quizá un método, pero este deriva de la esencia misma de la realidad que en tanto logos solo se aprehende cuando el pensamiento deja mostrar las cosas en sus propias articulaciones de sentido, en lugar de forzarlas arbitrariamente en ideas preconcebidas. De esta forma, Gadamer muestra que la crítica al método de las ciencias modernas tiene sus antecedentes, mucho antes del debate sobre las ciencias del espíritu del siglo XIX, en el corazón del pensamiento antiguo y su metafísica del logos.

Todos estos planteamientos hacen parte de la reapropiación hermenéutica de la filosofía griega, particularmente de la renovación de la dialéctica platónica que emprende Gadamer, y que, sin duda, constituye una de las fuentes de las que se nutre su propio pensamiento. No se debe pensar, sin embargo, que el recurso a Platón represente una superación, à la Heidegger, de la tradición filosófica que lo habría olvidado. Para Gadamer, por el contrario, la ciencia moderna nunca llegó del todo a renegar de su origen griego (cf. $V M, 551$ ), como se puede ver en el idealismo alemán y su esfuerzo por conciliar la nueva ciencia de la naturaleza con una metafísica especulativa. Ya hemos visto que este motivo está presente en Hegel quien retoma motivos de la metafísica antigua en su crítica al método científico. Pero ahora debe 
ser también claro por qué esta crítica pasa en Hegel por una renovación de la tradición dialéctica de los griegos. En efecto, dicha crítica se apoya en la visión de una pertenencia esencial entre ser y pensar que se remonta a Parménides, se desarrolla en Platón y Aristóteles, y que Hegel revive modernamente, ya no en la unidad del logos atemporal, sino en la unidad dialéctica del espíritu que se despliega en la historia. Como en los griegos, dialéctica es para Hegel un método y una forma de realización del pensamiento filosófico, pero este método se funda en una concepción metafísica del ser de lo real que, visto ahora como el espíritu que gana paulatinamente consciencia de sí mismo, recoge en sí, como suyo, el momento del pensar y del conocer. De este modo, también para Hegel, el verdadero conocimiento humano solo tiene lugar cuando la consciencia deja de lado sus pretensiones solo subjetivas y se abandona confiada al movimiento espiritual de lo real que la porta.

Pues bien, es esta tradición de la dialéctica, que más que un método encarna toda una postura sobre el ser y sobre el lugar del ser humano en él, la que la hermenéutica de Gadamer busca conscientemente renovar. Esta se propone desarrollar una teoría de la experiencia del comprender que muy pronto reconoce la estructura dialéctica que es inherente a este, pero, de nuevo, dicha dialéctica no es solo un rasgo más del comprender, sino que brota de la ontología que lo fundamenta. ${ }^{3}$ La renovación de la dialéctica que realiza Gadamer no tiene lugar como una simple prolongación de esta, sino como un auténtico diálogo con esta tradición que retoma sus elementos esenciales, pero los resignifica en el horizonte de la situación del presente. ${ }^{4}$ En este sentido, Gadamer reconoce la esencia de la dialéctica como unidad de ser y pensar o como "mediación total del pensamiento y el ser", pero la entiende ahora como una "trabazón de acontecer y comprender" ( $V M, 552)$, y mientras la dialéctica metafísica asegura esa unidad en el médium del logos o del espíritu hegeliano, Gadamer lo hace a partir del elemento del lenguaje. La tensa cercanía que liga su pensamiento con la dialéctica clásica la expresa Gadamer así:

La experiencia hermenéutica que intentamos pensar desde el centro del lenguaje no es seguramente experiencia del pensamiento en el mismo sentido que esta dialéctica del concepto que pretende liberarse por completo del poder del lenguaje. Y, sin embargo, también en la experiencia hermenéutica se encuentra algo parecido a una dialéctica, un hacer de la cosa misma, un hacer que a diferencia de la metodología de la ciencia moderna es un padecer, un comprender, un acontecer. ( $V M, 556$ y ss.)

Para aprehender la dialéctica que aquí se perfila conviene, entonces, examinar la concepción del lenguaje que está a su base. Evidentemente Gadamer no elabora una teoría del lenguaje en el sentido clásico, es decir, un análisis distanciado que tomara al lenguaje como su objeto para detectar en él sus rasgos, estructuras o reglas definitorias. Un proceder así, que por lo demás sigue siendo dominante en la tradición del análisis lógico del lenguaje, genera de entrada una distancia entre la consciencia subjetiva y su objeto que es

3 Desde aquí se puede entender la arquitectura de una obra como $V M$ que transita entre un análisis del comprender de las ciencias del espíritu en su segunda parte y las consideraciones ontológicas sobre el lenguaje en la tercera. En efecto, mientras en la segunda parte la dialéctica, como dialéctica de pregunta y respuesta, parece señalar la forma de realización del comprender (su procedimiento podríamos decir), en la tercera, que ahora examinamos, dialéctica es ante todo un reflejo del ser mismo de lo real. Nuestro propósito es determinar este momento ontológico de la dialéctica y volver retrospectivamente desde allí sobre el carácter metódico que esta puede adoptar.

4 En ese sentido, afirma Gadamer que con esto "no es que pretendamos renovar la doctrina clásica de la inteligibilidad del ser ni transpolarla al mundo histórico. Tal cosa no haría más que repetir a Hegel, una repetición que no se sostendría ni ante Kant y la experiencia de la ciencia moderna, ni menos aún ante una experiencia de la historia que ya no está guiada por el saber de ninguna redención" $(V M, 552)$. 
precisamente la que la hermenéutica se propone impugnar. La pregunta hermenéutica por el lenguaje no es por su lógica operativa, sino por la experiencia más inmediata que hacemos de este. Más que una teoría, lo que aquí se presenta es una fenomenología del lenguaje que indaga la manera en que este comparece primordialmente a la experiencia humana, antes de que esta, transformada en un comportamiento objetivante, haga de él un mero instrumento a su disposición. Para esta fenomenología, antes de que el lenguaje sirva como herramienta para describir el mundo o los estados internos del sujeto, y por supuesto mucho antes de que se nos presente en su carácter de estructura o como un conjunto de reglas sintácticas o gramaticales, el lenguaje comparece a nuestra experiencia como sentido, es decir, como apertura de un espacio de significatividad que nos convoca y nos atrae. En efecto, la palabra que alguien nos dirige, $o$ incluso aquella que simplemente escuchamos por azar, tienen algo de una fuerza gravitacional que nos arrastra e interpela, pues reconocemos en ellas un elemento profundamente humano. Incluso si se trata de una palabra quebradiza o difusa, y aún tratándose de una que proviene de una lengua ajena, la palabra que se emite o se escucha porta y abre consigo todo un horizonte de sentido que invita a ser compartido. Por supuesto que el lenguaje comunica y describe, pero esto solo es posible porque previamente él ha instaurado en su acontecer un campo semántico común donde luego se actualizan las significaciones concretas, y por supuesto siempre es posible examinar el lenguaje en su condición formal de estructura de reglas, pero esta es más bien una conducta secundaria y algo artificial, que tiene lugar mucho después de que el lenguaje atrae la atención sobre sí por su simple carácter de ser apertura inmediata de sentido.

Evidentemente, esta fenomenología del lenguaje no hubiera sido posible sin el análisis de la experiencia histórica que domina la segunda parte de VM. Guiado, en efecto, por la discusión sobre el sentido del conocimiento que es propio de las ciencias históricas del espíritu, Gadamer descubre el principio de la historia efectual según el cual la historia, más que una realidad objetivable para el conocimiento, encarna un horizonte vivo de sentido que condiciona y orienta nuestro entero ser en el mundo a través de esas referencias básicas de la praxis humana que Gadamer llama prejuicios, y que surgiendo de cada tradición constituyen nuestro ser histórico efectivo. ${ }^{5}$ Pues bien, el resultado de este análisis muestra que, más que un principio metafísico, la historia efectual, es decir, el poder efectivo de la historia sobre nuestra existencia comprensora, se vive por cada individuo, en cada época, como una experiencia inalienable que tiene lugar ante todo cuando la propia situación de sentido se ve interpelada: allí donde nos afecta la palabra de la tradición y nos vemos obligados a reconstituir de forma renovada la trama de significatividad que

5 En cuanto al principio de la historia efectual deriva para Gadamer en la tarea de "hacer conciencia" de la historia efectual, se despliega para la hermenéutica una serie de exigencias que son condiciones de una genuina comprensión y que pueden constituir así un proyecto de vocación más metodológica. En este sentido, se ha tratado de ver en los planteamientos de Gadamer las bases de una metodología de los estudios históricos muy cercana a la escuela de Koselleck, cf. David Petit, "La hermenéutica de Gadamer como fundamento teórico-filosófico de la historia conceptual en Reinhart Koselleck", Revista de la Academia 25 (2018): 6-23. Este esbozo de un "método hermenéutico" se puede hacer aún más evidente si se considera que la conciencia de la historia efectual se realiza para Gadamer al modo de una "fusión de horizontes" que requiere la ejecución controlada de ciertas labores que son peculiares de una comprensión convertida en tarea científica, cf. VM, 377. Charles Taylor ha explorado esta dirección más metódica de la hermenéutica al entender la fusión de horizontes como la tarea de la elaboración de un "lenguaje de contrastes transparente" de la que debe hacerse cargo el científico social, cf. El multiculturalismo y "la política del reconocimiento" (México: Fondo de Cultura Económica), 108; "Comprensión y etnocentrismo", en La libertad de los modernos (Madrid: Amorrortu, 1985), 211. Y para un análisis de la fusión de horizontes en clave científica, cf. Luis Eduardo Gama, "El lugar del otro en las ciencias humanas hermenéuticas", Nómadas 31 (2009): 125-137. En este artículo, sin embargo, nos proponemos abordar la cuestión del método desde su fondo ontológico más profundo que se encuentra en esta concepción del lenguaje y de su peculiar dialéctica, que Gadamer analiza en la parte final de VM. 
define nuestro mundo. La experiencia de la historia efectual tiene lugar así en el juego del sentido que es el lenguaje en tanto dialéctica de pregunta y respuesta, es decir, como la pregunta que encarna una tradición que ya no comprendemos y como la respuesta que nos vemos obligados a dar entonces para restablecer la fractura que ha sufrido el sentido.

Esta dimensión lenguájica del comprender que se atisba desde la finitud de la experiencia histórica es la que se aborda entonces fenomenológicamente en la tercera parte de VM. Desde este nuevo abordaje, el lenguaje no determina solo las preguntas y respuestas que van conformando y tejiendo la tradición histórica, y por lo mismo ya no se trata de manera eminente del lenguaje del historiador o el científico social. Se trata más bien, de manera más básica, de que el lenguaje, en la forma particular que adopta en cada lengua concreta (y no solo en los lenguajes especializados de los científicos sociales), se articula continuamente al paso que va trayendo al frente una experiencia de mundo que es compartida por todos los que participan de él. También la metafísica griega y la metafísica cristiana del verbo desarrollaron su concepción del ser al hilo de una concepción del lenguaje. En estos casos, empero, la diversidad de la palabra hablada siempre se recondujo a la unidad atemporal del logos o de la palabra divina. En Gadamer, en cambio, el lenguaje se piensa como unidad sí, pero como la unidad de un acontecer continuo de sentido que nunca encuentra reposo, de una apertura permanente de significatividad que nunca representa el despliegue pleno de un sentido infinito, porque cada posición de verdad que se haga efectiva en el lenguaje deja en latencia, por necesidad, otras posibles que no se realizan. Por ello, el lenguaje es un acontecer de sentido que es la huella de la insuperable finitud humana.

En este contexto, Gadamer habla del lenguaje como de un centro (Mitte) desde el cual se desarrolla toda nuestra experiencia del mundo y, en particular, la experiencia hermenéutica de la comprensión (cf. $V M$, 548). Por supuesto, hacer del lenguaje un centro no implica plantear un dualismo entre este y la periferia, de modo que el lenguaje ocuparía una posición privilegiada ante la cual experiencias no lenguájicas se rebajarían a simples instancias accesorias de segundo orden. Una posición así solo sería una forma más del logocentrismo que Derrida denuncia en toda postura metafísica. ${ }^{6}$ En realidad, cuando habla del lenguaje como centro, Gadamer solo quiere indicar que toda experiencia de mundo es lenguájica, no porque el lenguaje haya articulado ya el todo en una trama significativa cerrada, sino porque ella irrumpe siempre desde un punto situado en esa trama, y solo desde allí, como desde su centro, esta experiencia va realizándose al modo de un proceso de aperturas y cierres de sentido, de quiebres, de reformulaciones y de nuevos quiebres de lo significativo, que constituyen sin cesar la vida del lenguaje y la experiencia de lo real. En esto consiste, según Gadamer, la genuina dialéctica de la palabra que entonces ya no se dirige teleológicamente hacia la revelación del logos o del concepto hegeliano, situados ambos más allá del lenguaje natural, sino que gravita siempre en la dimensión interna de este mismo lenguaje en la cual cada palabra es como un centro pulsante que puede hacer resonar desde sí innumerables posibilidades de sentido y acepciones de mundo (cf. VM, 549). Con ello se entiende, porque, según un pasaje citado antes, mientras la dialéctica metafísica pretende liberarse del poder del lenguaje, la dialéctica hermenéutica busca entregarse a este, como al acontecer de aperturas de sentido que en él tiene lugar. De esta forma el lenguaje no tiene un centro: no existe una única constelación de sentido fija alrededor de la cual orbitaran todas las realizaciones concretas de una lengua o, lo que es lo mismo, cada una de estas instancias puede convertirse en centro en tanto todas representan un posible nodo desde el que se proyectan líneas de significación que articulan la verdad del mundo en configuraciones cambiantes.

6 Cf. Jacques Derrida, De la gramatología (México: Siglo XXI, 2007), 11-35. 
Esta fenomenología hermenéutica del lenguaje se reclama a sí misma como una forma de dialéctica porque conserva de esta tradición su atisbo fundamental de una pertenencia entre el pensar y el ser, aunque eliminando de esta toda posible connotación metafísica. En efecto, se trata ahora de determinar esta pertenencia no desde el presupuesto metafísico de un ser al que le es inherente el momento del pensar y del conocer, sino según la experiencia del lenguaje en tanto experiencia del mundo y del sentido. La evidencia fenomenológica más inmediata de este pertenecer del ser humano al mundo del sentido la encuentra Gadamer en la experiencia de la escucha. Escuchar es, en efecto, hacer evidente nuestra pertenencia al entramado de sentido del mundo, como ya lo mostró Heidegger, quien nos recordaba que nunca escuchamos meros ruidos, sino siempre sonidos llenos de significación (el viento en las hojas, el fuego que crepita o un auto que pasa). ${ }^{7}$ No obstante, así visto, este tipo de percepción de la escucha no difiere de la visual que también "ve" de inmediato cosas con sentido y no un fárrago impenetrable de colores o formas. Para Gadamer, en cambio, existe una verdadera primacía del oír sobre el ver (cf. VM, 553) que descansa en su capacidad de hacer evidente nuestra pertenencia al mundo, es decir, nuestra intimidad con el sentido. Efectivamente, mientras la vista se desliza por encima de la superficie coloreada del mundo sin aprehender la profunda densidad de su sentido, y por ello pudiendo siempre "retirarse" de su vinculación con las cosas, la escucha, sobre todo en tanto escucha del lenguaje, permanece ligada al horizonte de significatividad de lo real en sus distintas capas, y se requiere una actitud muy artificiosa para "retirar el oído" y romper nuestra pertenencia al mundo de sentido que nos habla.

Pero más allá de esta evidencia fenomenológica que aporta la escucha, Gadamer ilustra esta pertenencia hermenéutica con la dialéctica que entraba el acontecer de sentido que tiene lugar en el lenguaje con la comprensión humana. Es esta "trabazón de acontecer y comprender" la que representa el genuino sucedáneo hermenéutico, es decir, antimetafísico, de la identidad entre ser y pensar que ya los griegos identificaron. En efecto, para la hermenéutica, la comprensión se revela en último término como parte integral de ese acontecer continuo de sentido que ocurre en el lenguaje vivo, y no como un término o extremo independiente que objetivara como desde fuera las significaciones que desde allí brotan. Dicho de otra forma, la comprensión no representa el polo subjetivo ante el sentido objetivo que se articulara en el lenguaje. Toda forma de dualismo se encuentra aquí superada, porque, en realidad, el lenguaje como acontecimiento del sentido solo se hace real y efectivo en tanto es recogido por la comprensión y hecho real en una forma activa de interpretación, pero, a la vez, la comprensión e interpretación solo son posibles como respuestas a ese acontecer que nos interpela, y no como una actividad espontánea de una consciencia soberana y dueña de sí misma. Más que un dualismo, aquí se genera un auténtico círculo o, más exactamente, la versión ontológica del círculo hermenéutico que expresa de manera precisa la pertenencia que enlaza al ser humano con el ser de lo real en tanto acaecer de sentido. En consecuencia, en la trabazón de acontecer y comprender, no hay, en último término, más que un solo acontecer: una posibilidad de sentido que se perfila difusamente en las cosas, pero que solo se actualiza si la comprensión e interpretación humana la hace efectiva a través de una praxis concreta o de una forma de vida:

Visto desde el intérprete, 'acontecer' quiere decir que no es él el que, como conocedor, busca su objeto y 'extrae' con medios metodológicos lo que realmente se quiso decir y tal como realmente era (....) esto no es más que un aspecto exterior al verdadero acontecer hermenéutico; es el que motiva la ineludible disciplina metodológica. Sin embargo, el verdadero acontecer sólo se hace posible en la medida en que la

7 Martin Heidegger, Sein und Zeit (Tubinga: Max Niemeyer, 1967), \$34. 
palabra que llega a nosotros desde la tradición, y a la que nosotros tenemos que prestar oídos, nos alcanza

de verdad y lo hace como si nos hablase a nosotros y se refiriese a nosotros mismos (VM, 553).

Con este último pasaje, nos es posible anudar todas las reflexiones anteriores. Nuestro punto de partida fue la crítica de Gadamer al método científico moderno como una reflexión externa, frente a la cual el verdadero método se perfilaba como un "hacer de la cosas mismas". Esto motivó el recurso hermenéutico a la dialéctica que hemos detallado hasta el punto en que fue claro que este hacer de las cosas mismas no es otro que el hacer finito del lenguaje como apertura permanente del sentido. El lenguaje se reveló, entonces, como acontecer de sentido que solo en la comprensión gana realidad y efectividad histórica. La comprensión pertenece al acontecer como su condición y a la vez como su resultado o, lo que es igual, la existencia humana solo es tal por estar situada y condicionada por un mundo que, sin embargo, ella misma sostiene y reconfigura permanentemente. Toda esta ontología acontecimental del lenguaje representa el horizonte último de la crítica hermenéutica al método científico moderno. Es sobre el trasfondo de este acontecer que este se muestra en su "aspecto solo exterior", y que toda su disciplina y procedimentalismo se revela como algo apenas secundario. Pero atención, pues Gadamer no afirma que el método moderno sea falso per se, sino apenas externo o superficial. En consecuencia, no se trata en la hermenéutica de suprimir toda disciplina metódica de la comprensión, sino de asegurar, por lo pronto, que cualquiera que sea su diseño y configuración, esta no se absolutice de modo tal que pierda de vista el carácter acontecimental del sentido. Podemos, entonces, formular desde la hermenéutica algo así como un metaprincipio metodológico, un principio rector que debe orientar toda metodología del conocimiento. Este afirma que cualquier regla, procedimiento o principio metódico solo es legítimo si permite acontecer al sentido, es decir, si favorece la expresión de las posibilidades significativas que yacen latentes en los fenómenos mismos y contribuye a articularlas en configuraciones amplias de significación. Ateniéndose a este principio, y según las observaciones expuestas hasta aquí, procederemos en la segunda sección de este artículo a identificar algunos principios básicos de este "método hermenéutico".

\section{II}

Nos proponemos ahora derivar de esta ontología hermenéutica algunas indicaciones que pueden considerarse metodológicas en tanto toman la forma de prescripciones generales que orientan a un pensamiento riguroso en su aspiración de acceder a la verdad. Esta formulación requiere, sin embargo, precisiones adicionales. En primera instancia, se debe advertir que el "método" que se quiere esbozar aquí concierne a la investigación filosófica y no específicamente a aquella propia de las disciplinas científicas consolidadas. Por supuesto, al derivar de la tradición hermenéutica los principios identificados, han encontrado ya desarrollo en diversos análisis del tipo de conocimiento que brindan las ciencias sociales, pero nuestro interés, sin embargo, se limita a preguntar, de manera general, por los lineamientos que guían el despliegue del ejercicio filosófico, tal como lo entiende la filosofía hermenéutica. Por ello, se debe precisar, en segundo término, que, cuando hablamos en este contexto de orientaciones hacia el acceso a la verdad, entendemos "verdad" en un sentido justamente hermenéutico, es decir, no como una relación de "correspondencia con los hechos" de una realidad objetiva, sino de manera más básica como la "apertura o instalación de un campo de sentido" sobre el cual tiene lugar luego la praxis humana en general, incluida aquella forma de praxis consistente en la formulación de enunciados que correspondan con los hechos y que se suele llamar conocimiento. En resumen, de lo que se trata aquí es de identificar ciertos principios que orienten el ejercicio de un pensar hermenéutico en su tarea más básica que estriba, 
como se ha visto, en reconocer en la diversidad de los fenómenos del mundo las huellas del acontecer del sentido y en favorecer su despliegue.

El primero de estos principios tiene que ver con la cuestión de la objetivación, es decir, con la distancia y el grado de vinculación del que comprende respecto de aquello que se busca comprender. Como hemos ya señalado, una de las críticas de la hermenéutica a la metodología de la ciencia moderna es que esta desconoce la ligazón que une al que comprende con su objeto y hace del primero una consciencia subjetiva neutra que simplemente registra externamente los rasgos de una realidad que le resulta ajena. No obstante, el rechazo de esta objetivación radical no implica en la hermenéutica la afirmación de una cercanía o intimidad que ligara sin fisuras al individuo con el mundo que este busca comprender. Así como una comprensión genuina se entorpece si se rompe la vinculación con el mundo, en cuyo caso solo se alcanza, a lo sumo, una visión superficial de las conexiones causales entre de los fenómenos, del mismo modo la inmersión plena en una realidad que nos envuelve sin mediación no permitiría generar la distancia necesaria que requiere la comprensión. En ese sentido, Gadamer señala que el topos de la hermenéutica, es decir, el lugar donde puede florecer una auténtica comprensión es siempre un "punto medio de extrañeza y familiaridad" (cf. VM, 365). Ni la neutralidad de un observador externo ni la cercanía empática de un participante implicado aseguran la comprensión verdadera de un fenómeno. Así, un científico demasiado neutral no podría participar de las referencias de sentido que develan la esencia de ciertos fenómenos sociales, pero uno demasiado inserto en un espacio dado de significaciones no sería sensible a las mutaciones constantes que sufre este y solo promovería una compresión estándar de las cosas. De lo que se trata para el hermeneuta es de reconocer el grado de familiaridad que lo vincula al fenómeno que quiere comprender, de ser consciente de hasta qué punto él mismo está comprometido vitalmente con su significado, para, luego, a la luz de esta reflexión, poder identificar los límites más allá de los cuales este fenómeno pierde su alcance significativo y ser receptivo a aquello que, develando sus quiebres y fisuras, exige elaborar otro marco de comprensión. Llamaremos a este principio, que conviene ahora examinar más de cerca, el principio de la determinación del topos de la comprensión.

Sin elaborarlo expresamente como principio metodológico, Gadamer se refiere a esta exigencia de la comprensión que aquí planteamos como la tarea de sacar a luz los presupuestos desde los cuales se comprende o como la demanda que se plantea al intérprete de iluminar su propia situación. Desde otras aproximaciones teóricas, se han elaborado exigencias similares, particularmente en los debates sobre las prácticas de las ciencias que aspiran al conocimiento del mundo social. ${ }^{8}$ Aquí, sin embargo, no nos

8 Los planteamientos de Pierre Bourdieu sobre la reflexividad resultan a este respecto paradigmáticos. En su análisis de las condiciones de producción del conocimiento en las ciencias sociales, Bourdieu se esfuerza por elaborar una posición que evite los extremos del objetivismo y del subjetivismo, es decir, de lo que aquí hemos recogido como las posturas del "observador externo neutral" y del "participante implicado", en tanto modelos guías del científico social. Esta postura es la llamada reflexividad y exige del investigador, entre otras cosas, una atención permanente a las condiciones (institucionales, sociales, históricas) en que se produce el conocimiento o, lo que es lo mismo, una objetivación de lo que él llama el "campo científico"; cf. Pierre Bourdieu, Science de la science et reflexivité (París: Raison d’agir, 2001). Esta "objetivación del sujeto de la objetivación” resulta así muy cercana a la exigencia gadameriana de iluminar la situación del intérprete, a pesar de la postura crítica de Bourdieu con respecto a la hermenéutica. En el ámbito de la antropología, tuvo lugar un debate similar a partir del auge de la antropología interpretativa de Clifford Geertz, quien cuestionaba la autoridad del etnógrafo distanciado con argumentos cercanos a los que postula la hermenéutica en su crítica al objetivismo científico; cf. Clifford Geertz, La interpretación de las culturas (Barcelona: Gedisa, 1988). 
detendremos en estos desarrollos. Lo que nos interesa considerar, en cambio, es de qué manera esta iluminación de la situación interpretativa del que comprende puede tener lugar en el ámbito de la reflexión filosófica. Gadamer mismo avanza en esta dirección. Cuando su descripción inicial del comprender pone de manifiesto su pre-estructura, es decir, el conjunto de imágenes, nociones y concepciones previas que orientan toda interpretación al modo de anticipaciones de sentido, deja en claro que de esta descripción fenomenológica se deriva una tarea metódica: "una comprensión llevada a cabo desde una consciencia metódica intentará siempre no llevar a término directamente sus anticipaciones sino más bien hacerlas conscientes para poder controlarlas y ganar así una comprensión correcta desde las cosas mismas" (VM, 336). Este mismo pasaje pone en evidencia que esa iluminación de la propia situación no ocurre al modo de una introspección, pues lo que importa al hermeneuta en esta toma de consciencia de los prejuicios que lo determinan no es tanto una reflexión sobre sí mismo, sino "hallar la salida al círculo de las propias opiniones preconcebidas" ( $V M, 334)$ y estar abierto a la opinión del otro o, lo que es lo mismo, dejar que "el texto mismo pueda presentarse en su alteridad" ( $V M, 336)$. En ese sentido, determinar el topos de la comprensión no implica solo "asegurarse a sí mismo" dentro de su horizonte, sino ante todo elaborar desde allí una relación con lo otro, una que reconozca las continuidades y las rupturas de sentido (lo familiar y lo extraño) que articulan esta relación, de manera que ni se integre al otro de manera forzada en mi propio espacio de sentido ni se lo expulse de allí como si se tratase de una extrañeza insuperable. Gadamer brinda un ejemplo de aplicación de este principio en el ámbito filosófico (cf. VM, 336). Cuando al comienzo de Ser y tiempo Heidegger se propone replantear la pregunta por el sentido del ser, ${ }^{9}$ no aborda esta cuestión como si ella constituyera un ámbito objetivo que pudiera determinarse en sí mismo desde una mirada neutral. Al contrario, lo que él busca primero es establecer el horizonte propio desde el que se accede al problema. Este no es otro que la tradición de la metafísica occidental en la que Heidegger destaca algunos hitos esenciales (Aristóteles, Descartes, Kant y Hegel) a lo largo de los cuales se fue forjando la concepción dominante del ser que llega hasta él mismo. Pero elaborar esta tradición no es meramente reconocerse parte integral de ella, sino ante todo identificar lo que en ella resulta hoy insostenible. De esta forma, Heidegger determina el topos de su comprensión del problema del ser, no simplemente asimilando su cuestionamiento al que es propio de la metafísica, sino reconociendo a la vez sus sesgos y limitaciones. La cuestión del ser resulta así, en la óptica de Heidegger, familiar y extraña: constituida en medio de una tradición que le da sentido, pero que al tiempo la nubla y enrarece con el olvido del enigma fundamental que le es propio. Solo desde este topos ganado se puede ahora apuntalar una comprensión más auténtica y rigurosa de la pregunta por el ser: una que no la rebaje al problema de la determinación del fundamento de los entes, pero que tampoco la exilie al terreno de lo indeterminable e impensable que sobrepasa los límites de la razón y el pensamiento.

La tarea de la elaboración del topos de la comprensión debe entonces prevenir de un doble riesgo: evitar una objetivación radical del fenómeno a comprender que haga de este un simple dato al que puede ganar acceso una consciencia neutra, pero al tiempo evitar sucumbir en una pura cartografía introspectiva del que comprende, que olvide la alteridad insuperable de lo que comparece a la comprensión. Pese a estas prevenciones esta exigencia de abrir desde $m i$ horizonte una relación con lo otro, puede resultar aún demasiada autocentrada y requiere por ello acompañarse de un segundo principio que le sirve de complemento. Este se relaciona con lo que Gadamer llama la "anticipación de la perfección" (Vorgriff auf Vollkommenheit) que representa para él el "presupuesto formal que guía toda comprensión" (cf. VM, 363). De manera global, esta anticipación señala el supuesto fundamental de la comprensión de que

9 Heidegger, Sein und Zeit, \$6. 
aquello que queremos comprender representa una unidad completa de sentido. Sin esta suposición, en efecto, es decir, sin asumir que el fenómeno cuyo sentido queremos indagar es verdaderamente un fenómeno dotado de significatividad, ni siquiera nos tomaríamos el trabajo de comprender. Más aún, sin esta presuposición difícilmente el fenómeno comparecería ante nosotros como algo digno de ser comprendido. Ahora bien, suponer en el objeto de la comprensión una unidad de sentido no quiere decir simplemente adjudicarle inteligibilidad y racionalidad. ${ }^{10}$ Más que un presupuesto solo formal, se trata aquí de un principio con contenido, pues lo que se asume es que lo otro que me confronta representa potencialmente una verdad que, si bien al inicio es incomprensible, puede llegar a develarse en el curso de la comprensión como una posibilidad genuina de sentido que afecte sustancialmente el mundo y la situación del que comprende. Lo que se presupone en último término es que lo otro, cuando se comprende, puede llegar a representar una postura de sentido que corrige el mundo del intérprete en aspectos sustanciales, modificando las referencias que articulan su conocer y su actuar.

En $V M$, Gadamer plantea este principio de manera unilateral como un presupuesto solo del que comprende con respecto al fenómeno a comprender, de modo que la posible corrección que se entrevé solo tiene lugar en el sentido de que el intérprete puede ver alterarse su propio espacio de significatividad ante la verdad que destella del fenómeno ahora comprendido. Sin embargo, nosotros consideramos que esta corrección puede darse igualmente en la otra dirección, es decir, como la posibilidad de que la comprensión lograda por el intérprete sirva para precisar, corregir o esclarecer la propuesta de sentido que representa el fenómeno interpretado. Algo semejante plantea Gadamer en el campo de la interpretación de la obra de arte cuando afirma que nosotros, los espectadores y críticos, podemos llegar a comprender esta mucho mejor que lo que lo hizo su propio autor, o cuando a propósito de la comprensión histórica afirma que el sentido de un acontecimiento puede develarse mejor a aquellos que lo examinan con cierta distancia histórica que a sus protagonistas. Pero más allá de estos campos específicos, parece cierto que toda comprensión lograda es fundamentalmente una "mejor comprensión", tanto porque en ella se comprende mejor el sentido de lo que nos hace frente como por el hecho de que una buena interpretación de lo otro revierte en una mayor claridad sobre la situación hermenéutica del que comprende. Podemos, entonces, llamar principio de corrección a esta segunda preceptiva hermenéutica que señala que toda comprensión "mejora o corrige" potencialmente tanto la aprehensión lograda de las cosas como la autocomprensión de la situación de los propios individuos que interpretan. ${ }^{11}$

10 Esta es quizá la diferencia fundamental entre este principio gadameriano y el principio de caridad de Donald Davidson con el que muchas veces se lo relaciona; cf. Donald Davidson, Inquiries into Truth and Interpretation (Oxford: Clarendon Press, 1984), 195 y ss.

11 En la discusión sobre los fundamentos filosóficos de las ciencias sociales, es quizá Charles Taylor quien mejor ha recogido este principio. A partir de la base, en sí misma hermenéutica, de que el ser humano es la única criatura que se interpreta a sí mismo, Taylor considera que lo propio de las ciencias del hombre es que estas se ocupan de "objetos" que no son meras entidades dadas, sino entes cuyo ser está determinado por su propia autointerpretación. En ese orden de ideas, el conocimiento que aporta el científico social debe ser visto como la interpretación de una interpretación, es decir, como una interpretación disciplinada y rigurosa de las formas en que se conciben a sí mismos, en forma espontánea y poco consciente, los individuos y los grupos humanos. En consecuencia, estas ciencias tienen por objeto ayudar a corregir las percepciones erradas o parciales que las sociedades tienen de sí mismas y a sustituirlas por interpretaciones mejores; cf. Charles Taylor, "La interpretación y las ciencias del hombre", en La libertad de los modernos (Madrid: Amorrortu, 1985). En línea con estos planteamientos, pueden ponerse también los aportes de Anthony Giddens a la "nueva teoría social". Para Giddens, las ciencias sociales aplican una "doble hermenéutica", pues los conceptos que inventan los sociólogos son nociones de segundo orden que interpretan los marcos de significado de primer orden dentro de los cuales los actores sociales orientan su conducta. En tanto estos conceptos pueden ser 
Cabría preguntarse, sin embargo, si se trata, en realidad, de un principio de carácter metódico. La posibilidad de la corrección de la interpretación parece tan solo la descripción de un elemento estructural de la comprensión, pero no es claro que de esta descripción se derive algún elemento prescriptivo. No obstante, en esta se inscribe una tarea que complementa la labor de la elaboración del topos de la comprensión. Si esta última exige establecer una relación del intérprete con su "objeto otro", lo que queda claro ahora es que ese objeto debe elaborarse al modo de una configuración abierta de sentido y no como un dato cerrado o un hecho dado, y que la relación que se busca establecer no es tanto una conexión entre dos extremos ajenos entre sí, sino más bien el reconocimiento de los nexos de sentido ya existentes entre ellos, es decir, la mutua pertenencia vigente entre el individuo y el fenómeno que lo interpela. Solo como configuración abierta de significatividad el sentido del objeto a comprender puede ser "corregido" en nuevas interpretaciones más fieles y más completas, y la relación del intérprete con su objeto deja de ser la obra exterior de un sujeto que actúa sobre el mundo y se muestra como la pertenencia inherente a la "cosa misma". La tarea que aquí se exige al intérprete entonces no es otra que la de aprehender el fenómeno, no en la puntualidad de su manifestación inmediata, sino como mediación de un horizonte de sentido con el que también estamos vinculados, para, luego, desde este horizonte común, criticar y corregir lo establecido en mejores interpretaciones y autointerpretaciones. La tesis ontológica de Gadamer sobre la pertenencia dialéctica del comprender al ser de lo real revela aquí todo su potencial metodológico, pues develar la pertenencia del ser humano al mundo de sentido que se revela en el lenguaje requiere una disciplina metódica y un rigor crítico que no van de suyo.

Si la pregunta por el ser de Heidegger nos sirvió antes para ilustrar nuestro primer principio, la propia reflexión hermenéutica de Gadamer nos brinda un modelo de aplicación del segundo. En efecto, cuando al comienzo del capítulo 9 de VM Gadamer elabora su teoría del comprender en confrontación con la tradición ilustrada y su ideal de un conocimiento objetivo y libre de prejuicios, dicha confrontación no es solo un lujo accesorio, sino que tiene por objeto revelar la pertenencia de su propia filosofía a la tradición de la que quiere deslindarse. Asegurar esta pertenencia resulta fundamental, pues solo desde dentro del mismo espacio de significación es posible para Gadamer señalar las limitaciones de la autoconcepción de la consciencia ilustrada: su prejuicio contra el prejuicio, lo infundado de su combate contra la autoridad o de su anunciada superación de la antigüedad. Lo que se logra con ello no solo es una mayor claridad sobre las tareas de la propia hermenéutica, sino también una imagen más completa y matizada de la modernidad ilustrada. Ambas quedan "corregidas", por así decirlo, de interpretaciones sesgadas o falsificadoras.

Los principios de la determinación del topos de la comprensión y de la corrección son los principios centrales de una metodología hermenéutica que encarnan, respectivamente, las tareas descriptivas y críticas de la comprensión. Las primeras buscan asegurar la objetividad del comprender: identificar las anticipaciones de sentido del intérprete y refrenar su tendencia a acallar la verdad que brota de los fenómenos mismos; con las segundas, se aspira no solo a una comprensión correcta de las cosas, sino a ganar siempre una "mejor comprensión" que sirva de correctivo tanto a las auto-descripciones solo parciales de los actores sociales como a aquellas interpretaciones seudo-científicas contaminadas de sesgos

incorporados a la vida social y devenir nociones de primer orden, esta doble hermenéutica es la condición estructural que le permite a la ciencia social ser eminentemente teoría crítica; cf. Anthony Giddens, La constitución de la sociedad (Buenos Aires: Gedisa, 1984), 284. 
ideológicos. No se trata, como debe ya ser claro, de dos conjuntos independientes, sino de tareas que en buena medida se traslapan y complementan. ${ }^{12}$ Los dos principios, en efecto, se encuentran íntimamente asociados, pues los hemos postulado como maneras de revelar y asegurar el presupuesto ontológico de la mutua pertenencia entre la comprensión y el mundo, entre el intérprete y el acontecimiento de sentido. De esta pertenencia, que Gadamer, por su parte, apuntala fenomenológicamente, hemos hecho derivar estas prescripciones metódicas básicas. Sin embargo, nuestra exposición previa mostró que la ontología de la comprensión funda esta pertenencia ante todo en la idea del lenguaje como acontecer de sentido. De esta manera, veíamos, el comprender no irradia de una consciencia subjetiva, sino que surge del centro mismo del lenguaje, en tanto este comparece ante el ser humano como una apertura infinita de posibilidades de significación que interpela a la comprensión y la invita a concretar el sentido. Para concluir, queremos ahora examinar brevemente qué tipo de orientaciones metódicas pueden derivarse de esta ontología última.

Algunas formulaciones de Gadamer ya revisadas preforman, de manera rudimentaria, estas prescripciones. Se afirma, por ejemplo, que el verdadero método de la comprensión no es un hacer subjetivo como en la ciencia moderna, sino "un padecer, un acontecer" (cf. VM, 557), que su tarea no es una asimilación de lo otro, sino una "escucha" que deja oír lo otro en su "sentido propio y diferente" (cf. $V M, 376$ ), o que el esfuerzo hermenéutico "tiene como tarea poner al descubierto un todo de sentido en la multilateralidad de sus relaciones" (cf. VM, 564). Aquí queremos reunir estas someras observaciones en un tercer principio metódico de la hermenéutica que podemos formular como la exigencia de desarrollar una sensibilidad para el acontecer. Señalaremos, ahora, de manera solo provisional, cuatro direcciones en las que esta exigencia se puede realizar.

En primer lugar, por tratarse de una "sensibilidad", no se piensa aquí en una aprehensión de tipo teórico, sino en una forma de percibir sensiblemente el acontecer. Ahora bien, como señala Gadamer, la forma de percepción más cercana al comprender es la de la escucha, en tanto sentido que nos hace evidente la intimidad que nos liga con el espacio de significación de nuestro mundo. Lo que se pide, entonces, es desarrollar una escucha atenta a lo que acontece, pero esta escucha es primero que todo una forma de suspensión o interrupción de la comprensión que nos impide precipitar aceleradamente la elaboración de un sentido, y nos pide atender cuidadosamente lo que ocurre y dar tiempo a que los fenómenos comparezcan en su verdadero significado. La referencia a la escucha resulta así algo más que una metáfora, pues la escucha es el sentido atento que permite captar lo que no se muestra de inmediato, y hace la pausa necesaria para que se haga presente lo latente, como la liebre que habiendo percibido

$12 \mathrm{Si}$ aquí las presentamos de forma separada es también para poner de relieve, con el segundo principio, el aspecto crítico y emancipatorio de la hermenéutica de Gadamer que pasa muchas veces a un segundo plano. La vocación crítica de la hermenéutica es sujeto de debate desde la temprana confrontación de Gadamer con Habermas; cf. Jürgen Habermas, "La pretensión de universalidad de la hermenéutica”, en La lógica de las ciencias sociales (Madrid: Taurus), 1970; pasa por la propuesta de Ricoeur de una hermenéutica crítica; cf. Paul Ricoeur, Hermenéutica y acción (Buenos Aires: Docencia), 1985, y sigue presente en muchos debates actuales como en la tematización de una "hermenéutica diatópica" con la que De Sousa-Santos quiere contestar las figuras de una racionalidad excluyente y defensora del orden mundial hegemónico; cf. Boaventura de Sousa-Santos, Crítica de la razón indolente (Bilbao: Desclée de Brouwer, 2003). Otra vertiente de esta hermenéutica crítica, elaborada en clara oposición a Gadamer y desde el registro de la hermenéutica literaria, se encuentra en Denis Thouard, "Qu'est-ce que une herméneutique critique?", Methodos 2 (2002). 
un sonido no se precipita a la huida, sino que se inmoviliza y levanta las orejas. ${ }^{13}$ Escuchar el acontecer significa, entonces, resistir la tentación de consumar la comprensión con la elaboración rápida de una respuesta, y darse tiempo para que lo que acontezca se despliegue en la plena configuración de su verdad.

En segundo lugar, el principio demanda la tarea de percibir el acontecer, es decir, no entidades objetivadas o hechos que se asumen como dados, sino fenómenos que acontecen, esto es, eventos en permanente desarrollo que requieren de los seres humanos acciones continuas para mantener su vivacidad en un proceso de transformación constante. Algo así exige del filósofo una postura ante el mundo, no como ante algo constituido por sustancias o esencias cuyos rasgos fijos debieran luego determinarse, sino como ante un dinamismo de sentido en permanente reconstitución. Para poner un ejemplo del campo de la filosofía política, se trata de concebir algo como la democracia no como un fenómeno definido desde unos rasgos fijos, y menos como un conjunto determinado de instituciones, sino como un acto (o conjunto de actos) que solo se realiza desde prácticas concretas. Con esto se transforma la labor del pensador, pues ya no se trata de determinar de una vez y para siempre las propiedades esenciales de la democracia, sino de concebir el tipo de acciones y de praxis que la hacen real y efectiva. En ese orden de ideas, la democracia resulta ante todo un "proceso de democratización", y solo tendría existencia efectiva si se sostiene desde ciertos gestos y ejercicios que la inventan y reinventan sin cesar.

En tercer lugar, el principio de la sensibilidad para el acontecer debe considerar que se trata aquí del acontecer de sentido que es el lenguaje mismo. En este contexto, el lenguaje es visto por Gadamer como el centro desde el que brota el sentido que interpela al ser humano y motiva la comprensión. Como recordaremos, esta referencia al "centro del lenguaje" no implica que exista algo así como un núcleo único de sentido alrededor del cual gravitarían todos los enunciados y actos de habla, sino, justamente al revés, que el lenguaje se realiza desde múltiples centros de significación desde los que se proyecta una diversidad infinita de aperturas de la verdad, que ningún enunciado, en últimas, tiene la última palabra, pues solo es parte de un proceso incesante de elaboraciones y reelaboraciones del sentido de lo real. Ser sensible para el acontecer implica, entonces, desarrollar lenguajes que no cierren el sentido al imponer a la fuerza en los fenómenos los esquemas interpretativos habituales; lenguajes con la movilidad y el dinamismo semántico necesario para poder dar expresión a las variaciones y metamorfosis que acontecen y transforman constantemente el mundo de la praxis humana. Para el pensamiento filosófico, esto implica, entre otras tareas, la elaboración de conceptos fluidos y el abandono de un lenguaje meramente enunciativo por otro que privilegie la elaboración permanente del sentido en la confrontación constante con las cosas mismas que Gadamer llama conversación.

Esta demanda por una multiplicación de los centros del lenguaje no debe tomarse, sin embargo, como un llamado a la introducción arbitraria del sentido y a la profusión caprichosa e imaginaria de nuevas realidades y mundos posibles. Por ello, en cuarto lugar, ser sensible para el acontecer quiere decir ser sensible para fenómenos y acontecimientos que comparecen ante nosotros como aperturas de sentido que no dependen de nuestra voluntad y no se dejan moldear maleablemente a nuestro arbitrio, sino

13 Debo esta simpática imagen a mi colega de la Universidad de Nanterre Christian Berner, quien ha desarrollado el planteamiento de la necesidad de retardar la comprensión y demorarse en la experiencia de la ausencia de sentido que es la de la no comprensión. Hago referencia a varios artículos de este autor en esta dirección en las referencias. Sobre la escucha en la hermenéutica en conexión con la dialéctica, cf. Margarita Cepeda, "Dialéctica y escucha”, Ideas $y$ Valores 51, n. ${ }^{\circ} 120$ (2002): 25-30. 
que representan configuraciones autónomas de significación. Dichas configuraciones se componen, por cierto, de varias capas semánticas y admiten por ello múltiples relaciones de significación, pero son también horizontes limitados en los cuales "no todo vale". La tarea que se impone desde aquí toma forma, para Gadamer, en la realización de un pensar especulativo (cf. VM, 561) que no se impone a la realidad, sino que persigue el movimiento de los fenómenos mismos en las múltiples direcciones de significación que constituyen su acontecer.

Ser sensible al acontecer exige, entonces, no precipitar la comprensión, sino aguardar el despliegue del sentido de los fenómenos que tiene lugar como un proceso cambiante y no como la manifestación de una esencia oculta. Y esto demanda a su vez la elaboración de lenguajes sin centro capaces de seguir el movimiento de las significaciones de las cosas, en sus múltiples relaciones, esto es, de manera especulativa, y de pensarlo y concebirlo en nociones fluidas que permitan nuevas aperturas de verdad para lo real. Estas tareas, en conjunto con las que provienen de los otros dos principios, constituyen, a nuestro modo de ver, los elementos centrales del método hermenéutico de Gadamer.

\section{Bibliografía}

Berner, Christian. "Linterprétation est critique: Pour un dépassement des herméneutiques de la propriété". En Interpretazione e Trasformazione, editado por Alberto Romele, 97-113. Milán: Mimesis Edizioni, 2017.

Berner, Christian. "Mieux comprendre' autrement: Remarques sur une proposition téméraire". En Horizons de l'herméneutique philosophique, editado por Lambros Couloubaritsis y AntoninoMazzù, 213-233. Bruselas: Ousia, 2008.

Bourdieu, Pierre. Science de la science et reflexivité. París: Raison d'agir, 2001.

Cepeda, Margarita. "Dialéctica y escucha". Ideas y Valores 51, n. ${ }^{\circ} 120$ (2002): 25-30.

Davidson, Donald. Inquiries into Truth and Interpretation. Oxford: Clarendon Press, 1984.

Derrida, Jacques. De la gramatología. México: Siglo XXI, 2005.

De Sousa-Santos, B. Crítica de la razón indolente: Contra el desperdicio de la experiencia. Bilbao: Desclée de Brouwer, 2003.

Gadamer, Hans-Georg. Verdad y método I. Salamanca: Sígueme, 1996.

Gama, Luis Eduardo. "El lugar del otro en las ciencias humanas hermenéuticas y algunas perspectivas para América Latina”. Nómadas 31 (2009): 125-137.

Geertz, Clifford. La interpretación de las culturas. Barcelona: Gedisa, 1988.

Giddens, Anthony. La constitución de la sociedad: Bases para una teoría de la estructuración. Buenos Aires: Gedisa, 1984.

Habermas, Jürgen. "La pretensión de universalidad de la hermenéutica". En La lógica de las ciencias sociales, 277306. Madrid: Taurus, 1970.

Heidegger, Martin. Sein und Zeit. Tubinga: Max Niemeyer, 1967.

Petit, David. "La hermenéutica de Gadamer como fundamento teórico-filosófico de la historia conceptual en Reinhart Koselleck". Revista de la Academia 25 (2018): 9-26.

Ricoeur, Paul. Hermenéutica y acción. Buenos Aires: Docencia, 1985.

Taylor, Charles. El multiculturalismo y "la política del reconocimiento". México: Fondo de Cultura Económica, 1993.

Taylor, Charles. "La interpretación y las ciencias del hombre". En La libertad de los modernos, 143-198. Madrid: Amorrortu, 1985.

Taylor, Charles. "Comprensión y etnocentrismo". En La libertad de los modernos, 199-222. Madrid: Amorrortu, 1981.

Thouard, Denis. Herméneutique et critique: Bollack, Szondi, Celan. Villeneuve d’Ascq: Septentrion, 2012.

Thouard, Denis. “Qu'est-ce que c'est une herméneutique critique?". Methodos 2 (2002). https://doi.org/10.4000/ methodos.100 